\title{
Antibacterial Activity and Protection Efficiency of Polyvinyl Butyral Nanofibrous Membrane Containing Thymol Prepared through Vertical Electrospinning
}

\author{
Wen-Chi Lu ${ }^{1,2, \dagger}$, Ching-Yi Chen ${ }^{1,+} \oplus$, Chia-Jung Cho ${ }^{1, *,+}$, Manikandan Venkatesan ${ }^{1, \dagger}$, Wei-Hung Chiang ${ }^{3}$, \\ Yang-Yen $\mathrm{Yu}^{4}{ }^{(\mathbb{D}}$, Chen-Hung Lee ${ }^{5, *}$, Rong-Ho Lee $\left.{ }^{6}{ }^{(}\right)$, Syang-Peng Rwei ${ }^{1}(\mathbb{D})$ and Chi-Ching Kuo ${ }^{1, *}$
}

1 Research and Development Center of Smart Textile Technology, Institute of Organic and Polymeric Materials, National Taipei University of Technology, Taipei 10608, Taiwan; wcl2320@mail.lit.edu.tw (W.-C.L.); duckfat8@gmail.com (C.-Y.C.); manikandanchemist1093@gmail.com (M.V.); f10714@ntut.edu.tw (S.-P.R.)

2 Department of Applied Cosmetology, Lee-Ming Institute of Technology, New Taipei City 243083, Taiwan

3 Department of Chemical Engineering, National Taiwan University of Science and Technology,

Taipei 10607, Taiwan; whchiang0102@gmail.com

4 Department of Materials Engineering, Ming Chi University of Technology, New Taipei City 24301, Taiwan; yyyu@mail.mcut.edu.tw

5 Division of Cardiology, Department of Internal Medicine, Chang Gung Memorial Hospital-Linkou, Chang Gung University College of Medicine, Tao-Yuan 333, Taiwan

Citation: Lu, W.-C.; Chen, C.-Y.; Cho, C.-J.; Venkatesan, M.; Chiang, W.-H.; Yu, Y.-Y.; Lee, C.-H.; Lee, R.-H.; Rwei, S.-P.; Kuo, C.-C. Antibacterial Activity and Protection Efficiency of Polyvinyl Butyral Nanofibrous Membrane Containing Thymol Prepared through Vertical Electrospinning. Polymers 2021, 13, 1122. https://doi.org/ $10.3390 /$ polym 13071122

Academic Editors: Andrada Serafim and Stefan Ioan Voicu

Received: 28 February 2021

Accepted: 25 March 2021

Published: 1 April 2021

Publisher's Note: MDPI stays neutral with regard to jurisdictional claims in published maps and institutional affiliations.

Copyright: (c) 2021 by the authors Licensee MDPI, Basel, Switzerland. This article is an open access article distributed under the terms and conditions of the Creative Commons Attribution (CC BY) license (https:// creativecommons.org/licenses/by/ $4.0 /)$
Department of Chemical Engineering, National Chung Hsing University, Taichung 402, Taiwan; rhl@dragon.nchu.edu.tw

* Correspondence: ppaul28865@mail.ntut.edu.tw (C.-J.C.); chl5265@gmail.com (C.-H.L.); kuocc@mail.ntut.edu.tw (C.-C.K.); Tel.: +886-2-2771-2171 (ext. 2407) (C.-C.K.); Fax: +886-2-27317174 (C.-C.K.)

$+\quad$ These authors contributed equally to this work.

Abstract: Human safety, health management, and disease transmission prevention have become crucial tasks in the present COVID-19 pandemic situation. Masks are widely available and create a safer and disease transmission-free environment. This study presents a facile method of fabricating masks through electrospinning nontoxic polyvinyl butyral (PVB) polymeric matrix with the antibacterial component Thymol, a natural phenol monoterpene. Based on the results of Japanese Industrial Standards and American Association of Textile Chemists and Colorists methods, the maximum antibacterial value of the mask against Gram-positive and Gram-negative bacteria was 5.6 and 6.4, respectively. Moreover, vertical electrospinning was performed to prepare Thymol/PVB nanofiber masks, and the effects of parameters on the submicron particulate filtration efficiency (PFE), differential pressure, and bacterial filtration efficiency (BFE) were determined. Thorough optimization of the small-diameter nanofiber-based antibacterial mask led to denser accumulation and improved PFE and pressure difference; the mask was thus noted to meet the present pandemic requirements. The as-developed nanofibrous masks have the antibacterial activity suggested by the National Standard of the Republic of China (CNS 14774) for general medical masks. Their BFE reaches $99.4 \%$, with a pressure difference of $<5 \mathrm{mmH}_{2} \mathrm{O} / \mathrm{cm}^{2}$. The mask can safeguard human health and promote a healthy environment.

Keywords: electrospinning; nanofibrous membrane; antibacterial activity; protection efficiency; mask

\section{Introduction}

Particulate matter (PM) pollution, due to industrial development and living environment change, worsens air quality and causes severe health problems, such as respiratory diseases, cardiovascular diseases, and allergies [1]. In the recent years, various influenza and coronavirus diseases have become prevalent, causing harm to human health and large economic losses [2-4]. Masks can prevent droplets and PM from invading the human body and prevent respiratory infections. The types of masks include cotton masks, general medical masks, surgical masks, activated carbon masks, and N95 masks [5,6]. N95 masks 
have the highest ability to filter out PM with a $\leq 2.5-\mu \mathrm{m}$ diameter (PM2.5), but because of their favorable adhesion, they can cause breathing problems and are thus unsuitable for long-term wear and general protection. To keep out epidemic virus droplets, PM with a $\leq 10-\mu \mathrm{m}$ diameter (PM10), and some PM2.5, and thus protect the human body, surgical and medical masks must be worn correctly and be suitable for long-term wear.

General medical masks are made of polypropylene (PP), and their manufacturing method mainly involves spun bonding or melt blowing. The outer and inner layers of the mask are composed of PP spun-bond nonwoven fabric. The outer layer must repel water to prevent the penetration of blood, body fluids, and other potentially infectious substances. The inner layer is a face affinity layer, which can absorb moisture generated during breathing and thus keep the face dry and comfortable. The middle layer of the mask is a melt-blown nonwoven fabric layer, which is used to filter PM and bacteria. However, when the fibers of the middle layer are thick, the material's efficiency in filtering very small particles is low and thus high efficiency and low impedance cannot be achieved. Therefore, polytetrafluoroethylene membranes [7] or polyvinyl butyral (PVB) can be used as the matrix for preparing nanofiber membranes through electrospinning. Nanofibers have small diameter, high porosity, and internal pores [8-13], so they have favorable connectivity and high air permeability [14-18], which are conducive to capturing ultrafine particles. Nanofibers thus have high efficiency in filtering PM $[19,20]$. Many electrospun fiber membrane types have been manufactured as media for air filtration; the most common are those made from uniform and monostructured nanofibers, including ultrafine nylon 6 fibers [21-23], polyethylene oxide nanofibers [24], alumina nanofibers [25], and polyester nanofibers [26-29]; however, these materials cannot filter bacteria or viruses in the air.

Thymol (2-isopropyl-5-methyl phenol) is a monoterpene phenol found in the essential oils of herbal plants [30]. Many studies have shown that Thymol has antibacterial and antifungal properties [31]. Marino et al. [32] reported that Thymus vulgaris L. essential oil has antibacterial activity against both Gram-negative bacteria (e.g., Escherichia coli) and Gram-positive bacteria (e.g., Staphylococcus aureus). By employing the agar dilution method, Nostro et al. [33] found that Thymol has antibacterial effects and sensitivity for various types of $S$. aureus. Kavoosi et al. [34] mixed gelatin films with different concentrations of Thymol to test its antibacterial activity against E. coli, Pseudomonas aeruginosa, Bacillus subtilis, and S. aureus for potential use as an antibacterial nano wound dressing.

Some scholars have blended Thymol with polymer materials to make nanofiber membranes and tried to develop dressings for wound healing, such as by adding Thymol to poly( $\varepsilon$-caprolactone) and polylactic acid through electrospinning technology to prepare nanofibrous mats $[11,35]$. Thymol has also been added in situ to chitosan/polyethylene glycol fumarate to prepare hydrogel wound dressings. A study demonstrated that hydrogels containing Thymol have favorable mechanical properties and excellent antibacterial activity against both Gram-negative and -positive bacteria, and they can be applied in a dressing for infected wounds with a moderate amount of exudate [36].

The main mechanisms through which fibrous materials filter dust and particles are the interception effect, inertial deposition, Brownian diffusion, the electrostatic effect, and the gravity effect. Effective filtration of dust and particles by the filter materials in a mask is achieved through a combination of these five effects [37]. In the present study, Thymol was mixed with PVB through electrospinning to prepare antibacterial nanofiber membranes. Antibacterial property and protection efficiency tests were conducted to ensure that the developed medical masks meet performance specifications and have antibacterial effects.

\section{Experimental}

\subsection{Materials and Microorganisms}

Polyvinyl butyral (PVB, B18-HX, $M_{\mathrm{W}} \sim 100,000$, Chang Chun Co., Taipei, Taiwan) was used as the matrix of the nanofibrous membranes. Ethanol (95\%) was used as a solvent purchased from I-Chang Chemical Co. ROC. Thymol (5-Methyl-2-(propan-2-yl)phenol) was supplied by Scharlab TI0080 (99\% purity). The antibacterial activities of Thymol- 
containing PVB nanofibrous mats were evaluated using Staphylococcus aureus (S. aureus) (ATCC 6538), Klebsiella pneumoniae (K. pneumoniae) (ATCC 4352), Escherichia coli (E. coli) (ATCC 8739), which were obtained from the Bioresource Collection and Research Center (BCRC), Taipei, Taiwan.

\subsection{Preparation of PVB Antibacterial Nanofibrous Membrane Containing Thymol}

Thymol/PVB nanofibrous membranes were fabricated by vertical electrospinning technique. Primarily, $5 \mathrm{wt} \%$ of PVB polymer solution was prepared by dissolving $25 \mathrm{~g}$ of PVB powder in $475 \mathrm{~g}$ of ethanol solvent with magnetic stirring for $2 \mathrm{~h}$ at room temperature and obtained transparent solution. Subsequently, different amounts of Thymol powder were added to the above mixture with vigorous stirring to obtain the homogenous solution, various compositions of Thymol/PVB electrospinning solutions as shown in Table 1 . The prepared Thymol/PVB electrospun solution was loaded into the plastic syringe containing a stainless needle (22-gauge stainless). A syringe pump (KDS-200, KD Scientific., Holliston, MA, USA) was used to feed the electrospinning solution with a fixed feeding rate of $0.72 \mathrm{~mL} / \mathrm{h}$. A high-voltage power supply (SM3030-24P1R, YOU-SHANG TECHNICAL CORP) was employed, and the applied voltage was $27 \mathrm{kV}$. The distance from tip to the collector was fixed at $10 \mathrm{~cm}$, and the collecting lasted for $7 \mathrm{~h}$.

Table 1. Various ratios of the Thymol/polyvinyl butyral (PVB) electrospinning solutions.

\begin{tabular}{cccc}
\hline Thymol:PVB $(w: w)$ & Thymol (g) & PVB (g) & $\mathbf{5 ~ w t} \%$ PVB (g) \\
\hline $0: 1$ & 0 & 2.5 & 50 \\
$0.2: 1$ & 0.5 & 2.5 & 50 \\
$0.4: 1$ & 1 & 2.5 & 50 \\
$0.6: 1$ & 1.5 & 2.5 & 50 \\
$0.8: 1$ & 2 & 2.5 & 50 \\
$1: 1$ & 2.5 & 2.5 & 50 \\
\hline
\end{tabular}

\subsection{Preparation of Thymol/PVB Antibacterial Nanofibrous Masks}

A result from the antibacterial preliminary test $0.6: 1$ ratio of Thymol/PVB nanofibrous membrane shows strong antibacterial effect against S. aureus, K. pneumoniae, and E. coli. Therefore, this optimized ratio was used in a vertical electrospinning device (SC-PME50, COSMI) to prepare the Thymol/PVB composite antibacterial nanofibrous mask. Since the vertical electrospinning device has many advantages, such as the needle can be moved left and right, collection area can be rotated, speed can be controlled, and a large-area nanofibrous membrane with better uniformity can be obtained. To this interest, the composite electrospun solution was taken into a $15 \mathrm{~mL}$ syringe, a stainless 22-gauge needle installed on the needle auxiliary moving mechanism. Relevant parameters were adjusted according to the experimental design, as shown in Table S1. Figure 1 represents the basic work function of three-layer facemask.

\subsection{Surface Observation of Nanofiber Membranes}

A scanning electron microscope (SEM) (JSM-6510, JEOL, Tokyo, Japan) was used to analyze the surface morphology of inner, outer, and middle layers of commercial mask fabrics and different Thymol/PVB electrospun nanofibrous membranes with varying electrospinning parameters. Diameters of uniformly distributed nanofiber were calculated from the SEM image. 


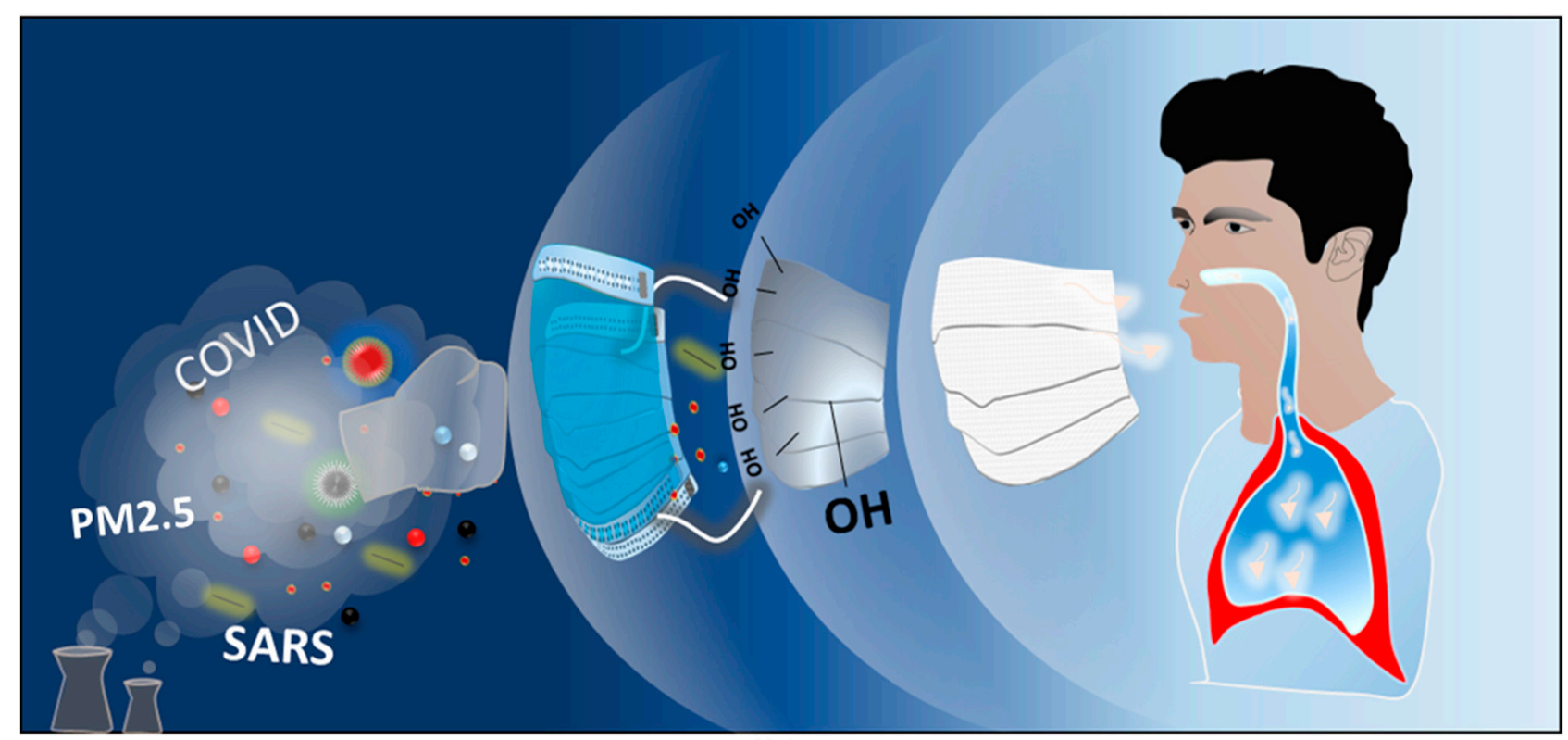

Figure 1. Schematic diagram of the electrospun Thymol/PVB nanofibrous facemask.

\subsection{Antibacterial Activity}

\subsubsection{Antibacterial Qualitative Tests}

Two qualitative methods were used to evaluate the antibacterial activities of PVB nanofibrous membranes containing Thymol, described below:

Japanese Industrial Standards (JIS) L1902 (Halo method): antibacterial qualitative tests were determined with adherence to the procedure of JIS L1902 method [38,39] (Halo method), performed by observing the zone of inhibition to evaluate the antibacterial properties of textiles. The method is suitable for textiles process by leaching antibacterial agents. The test methods were explained as follows:

A known weight of test samples was added to observe whether the Petri dish had a zone of inhibition; we measured the width of the sample (D) and the sum of the width of the sample and the zone of inhibition (T); then calculated the width of the zone of inhibition (W) with the following formula (1), and the result is expressed as an average $0.1 \mathrm{~mm}$.

$$
\mathrm{W}=(\mathrm{T}-\mathrm{D}) / 2
$$

American Association of Textile Chemists and Colorists (AATCC) 147 method (Parallel Streak method): the antibacterial qualitative tests were carried out in accordance with the procedures of AATCC147 method (Parallel Streak method). This method also helps to evaluate the antibacterial properties of textiles and it is suitable for textiles process by leaching antibacterial agents. The testing process was explained as follows:

(1) CZ: Clear zone of inhibition

(2) I: Inhibition of growth under the sample only

(3) NI: No inhibition of growth

\subsubsection{Antibacterial Quantitative Test}

JIS L1902 (Absorption method) testing method serves the quantitative information of antibacterial properties for the antibacterial textile products. The testing procedure was expressed as follows:

(1) The growth value on the control (F) should be $\geq 1.0$.

$$
\mathrm{F}=\log \mathrm{C}_{\mathrm{t}}-\log \mathrm{C}_{\mathrm{o}}
$$

$\log C_{t}$ : The average logarithm of the number of bacteria after $18-24 \mathrm{~h}$ inoculation of the control sample 
$\log C_{\mathrm{o}}$ : The average logarithm of the number of bacteria recovered from the control at the beginning of contact time

(2) Antibacterial activity value (A) should be $\geq 2.0$, which means the sample has antibacterial effect, according to the descriptions of JIS L1902.

$$
A=\left(\log C_{t}-\log C_{o}\right)-\left(\log T_{t}-\log T_{o}\right)=F-G
$$

G: The growth value on the sample

$\log \mathrm{T}_{\mathrm{t}}$ : The average logarithm of the number of bacteria after $18-24 \mathrm{~h}$ inoculation of the sample

$\log T_{0}$ : The average logarithm of the number of bacteria recovered from the sample at the beginning of contact time

\subsubsection{Particulate Filtration Efficiency (PFE)}

Following the procedure of National Standards of the Republic of China (CNS) 14,755 [40], the Automated Filter Tester (Model 8130, TSI, Shoreview, Minnesota, MN, USA) was used to measure the submicron particulate filtration efficiency or penetration efficiency of the masks to understand the protection performance of the masks. The definition of submicron particulate filtration efficiency as follows:

PFE: The ratio of the aerosol concentration captured by the mask to the original upstream aerogel concentration.

Penetration efficiency $(\%)=($ aerosol concentration through the mask) / (upstream air aerosol concentration) $\times 100 \%$

Protection efficiency $(\%)=100-$ penetration efficiency $(\%)$

Inhalation resistance: the ventilation resistance generated by a certain flow of air in the inhalation direction of the mask.

\subsubsection{Differential Pressure of Air Exchange}

According to CNS 14,777 (Test Method for Air Exchange Pressure of Medical Masks) Section 3, the tester of air exchange pressure (TTRI, TW) was used to measure the differential pressure of air exchange of the mask, to understand the breathability of the mask, and to evaluate whether it will cause breathing difficulties when wearing.

\subsubsection{Bacterial Filtration Efficiency (BFE)}

Following the procedure of CNS 14775, the Bacterial Filtration Efficiency (TTRI, TW) of the synthesized mask was calculated. A formed bacteria (S. aureus biological) aerogel size is approximately $(3.0 \pm 0.3) \mu \mathrm{m}$, which is controlled by the nebulizer system. The percentage of bacteria absorption before and after filtering through the mask and rate of applied pressure was estimated. The results were subjected to the following equation to calculate the percentage of BFE. The same procedure was followed for the 30 commercial masks to compare the obtained results.

$$
\text { BFE }(\%)=100 \times(\mathrm{C}-\mathrm{T}) / \mathrm{C}
$$

C: Average number of total plate count on the control.

T: Total plate count on the sample.

Calculate the average particle size of the aerosol by formula (6), which should be (3.0 \pm 0.3$) \mu \mathrm{m}$.

Average particle size $(\mathrm{MPS})=\Sigma(\mathrm{An} \times \mathrm{Sn}) / \Sigma \mathrm{An}=(\mathrm{A} 1 \times 7.0+\mathrm{A} 2 \times 4.7+\mathrm{A} 3 \times$

$$
3.3+\mathrm{A} 4 \times 2.1+\mathrm{A} 5 \times 1.1+\mathrm{A} 6 \times 0.65) /(\mathrm{A} 1+\mathrm{A} 2+\mathrm{A} 3+\mathrm{A} 4+\mathrm{A} 5+\mathrm{A} 6)
$$

An: The number of bacteria in the petri dish of this stage

Sn: The particle size of the aerosol collected by the sampler at this stage 


\section{Results and Discussion}

\subsection{Antibacterial Qualitative Analysis for Nanofibrous Membrane of Thymol/PVB Blenders}

Antibacterial qualitative analysis of the nanofibrous membranes was performed using the JIS L1902 and AATCC 147 standardized methods. Although no inhibition zones were found in samples of different compositions, to improve the inhibition zones, various methods were employed, such as adding a surfactant [41] and increasing the contact opportunities for bacterial liquid with nanofiber membrane (by using nets, pressurized glass sheets, and alumina foil). The addition of a surfactant can affect nanofiber surface morphology [42]. S. aureus were used as a testing agent in the JIS L1902 and AATCC 147 qualitative methods to evaluate the antibacterial effects of Thymol/PVB nanofibrous membranes. Although, as shown in Table 2 and Figure S1, spraying the tested bacteria liquid on the nanofibrous membrane or net-like architecture did not form any contact with the substrate. Even applying gentle pressure using a glass plate, this lack of interface formation results to fail the formation of the inhibition zone. In contrast, Group A and Group $C$ showed the formation of zone inhibition on alumina foil with a high concentration ratio of Thymol in PVB (1:1). However, even though the width of the inhibition zone increased slightly, the difference was not large.

Table 2. Qualitative analysis of antibacterial properties of Thymol/PVB nanofibrous membranes with different proportions.

\begin{tabular}{|c|c|c|c|c|}
\hline \multirow{2}{*}{$\begin{array}{l}\text { Method } \\
\text { Carrier }\end{array}$} & \multicolumn{2}{|c|}{ JIS L1902 (Halo Method) } & \multicolumn{2}{|c|}{ AATCC147 (Parallel Streak Method) } \\
\hline & Aluminum Foil & Net & Aluminum Foil & Net \\
\hline Pressing with glass & none & yes & yes & yes \\
\hline group & A & $\mathrm{B}$ & $\mathrm{C}$ & $\mathrm{D}$ \\
\hline \multicolumn{5}{|l|}{ Thymol:PVB $(w: w)$} \\
\hline $0: 1$ & ${ }^{c} \mathrm{NI}$ & ${ }^{\mathrm{c}} \mathrm{NI}$ & ${ }^{c} \mathrm{NI}$ & ${ }^{c} \mathrm{NI}$ \\
\hline $0.2: 1$ & ${ }^{c} \mathrm{NI}$ & ${ }^{c} \mathrm{NI}$ & ${ }^{c} \mathrm{NI}$ & ${ }^{c} \mathrm{NI}$ \\
\hline $0.4: 1$ & ${ }^{c} \mathrm{NI}$ & ${ }^{\mathrm{c}} \mathrm{NI}$ & ${ }^{c} \mathrm{NI}$ & ${ }^{\mathrm{c}} \mathrm{NI}$ \\
\hline $0.6: 1$ & ${ }^{c} \mathrm{NI}$ & ${ }^{c} \mathrm{NI}$ & ${ }^{c} \mathrm{NI}$ & ${ }^{c} \mathrm{NI}$ \\
\hline $0.8: 1$ & ${ }^{\mathrm{a}} \mathrm{CZ} 2.0 \mathrm{~mm}$ & ${ }^{c} \mathrm{NI}$ & ${ }^{\mathrm{a}} \mathrm{CZ} 2.1 \mathrm{~mm}$ & ${ }^{c} \mathrm{NI}$ \\
\hline $1: 1$ & ${ }^{\mathrm{a}} \mathrm{CZ} 5.1 \mathrm{~mm}$ & ${ }^{c} \mathrm{NI}$ & ${ }^{\mathrm{a}} \mathrm{CZ} 6.4 \mathrm{~mm}$ & ${ }^{c} \mathrm{NI}$ \\
\hline
\end{tabular}

${ }^{\mathrm{a}} \mathrm{CZ}$ : Clear zone of inhibition, ${ }^{\mathrm{c}} \mathrm{NI}$ : No inhibition of growth.

The inhibition zone may not have appeared because Thymol and PVB are insoluble in water, meaning that the probability of Thymol coming into contact with the inoculum was low. The weight of the sample in the antibacterial film was 4.76 times that in the nanofibrous membrane; that is, the content of the nanofiber membrane per unit area was low (Table S2). The nanofibrous membrane had a network structure, and actual contact with the bacterial liquid only occurred on the fiber mesh surface; however, the inhibition zone could only be produced when the antibacterial substance was in uniform contact with the bacterial liquid. For these reasons, the zone of inhibition was difficult to observe when the nanofibrous membranes were tested using the qualitative method.

\subsection{Antibacterial Quantitative Analysis for Thymol/PVB Nanofibrous Membranes}

The results in 3.1 showed that the qualitative method was not suitable for evaluating the antibacterial activity of Thymol/PVB nanofibrous membranes. Therefore, a quantitative determination was performed based on Absorption method from JIS L1902 to analyze the antibacterial activity of Thymol/PVB nanofibrous membranes on Gram-positive (S. aureus), and Gram-negative (K. pneumoniae and E. coli) bacteria.

\subsubsection{Staphylococcus aureus}

The antibacterial activity of the Thymol/PVB nanofibrous membranes on S. aureus is displayed in Table S3 and Figure 2a. According to the description of JIS L1902, when the antibacterial activity value exceeds 2.0 , the samples are considered to have antibac- 
terial properties [43-46]. With the addition of Thymol to PVB, the bacterial growth was considerably reduced. For example, considering Thymol $/ \mathrm{PVB}=0.2: 1$ nanofiber with an antibacterial value of 2.8, this increment is attributed to the phenolic hydroxy functional group of Thymol. Consequently, a maximum amount of antibacterial value 6.4 was obtained from the optimized ratio of 0.6:1. However, further addition of Thymol does not cause any changes in it and clearly shows the saturated ratio to PVB. Therefore, enhancing the proportion of Thymol in PVB leads to increasing antibacterial activity toward S. aureus bacteria.
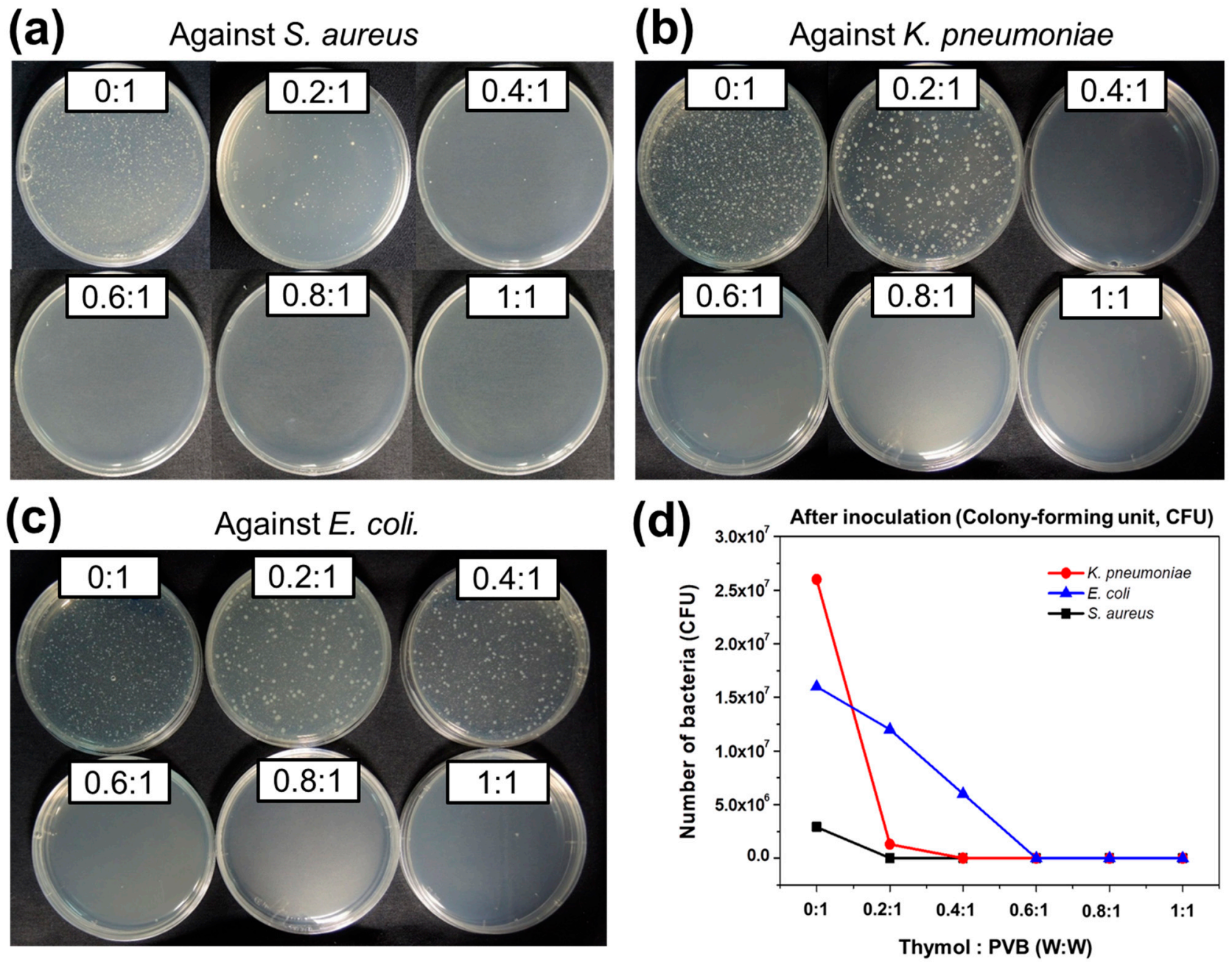

Figure 2. Quantitative results of antibacterial activity of Thymol/PVB nanofibrous membranes against (a) Staphylococcus aureus, (b) Klebsiella pneumonia, (c) Escherichia coli. (d) Comparison of the bacterial counts after culturing the three bacteria with Thymol/PVB fibrous membranes.

\subsubsection{Klebsiella pneumoniae}

The study of antibacterial effects of Thymol/PVB nanofibrous membranes against K. pneumoniae were monitored for 18-24 h. The control group growth value (F) should have been $>1.0$ and the test conditions were established. Table S4 and Figure $2 \mathrm{~b}$ display that bacteria growth was controlled as the proportion of Thymol increased. Antibacterial activity value also reached a maximum of 6.4 when the ratio of Thymol: PVB was 0.4:1. Other proportions also provide the same result.

\subsubsection{Escherichia coli}

As shown in Table S5 and Figure 2c, the quantitative antibacterial effect of the various nanofibrous membranes against $E$. coli was in favorable agreement with the testing results 
for other bacteria. However, the Thymol/PVB (0.6:1) nanofibrous membrane exhibited considerable enhancement, with a value of 6.4. Therefore, enhancing the proportion of Thymol in PVB resulted in higher antibacterial activity.

A comparison of the antibacterial activity values of PVB and various-ratio Thymol/PVB nanofibrous membranes for three bacterial types is presented in Table S6. The PVB nanofiber membrane without Thymol exhibited no response to the bacterial colonization. A significant reduction in bacterial growth was discovered for the Thymol/PVB nanofiber membranes, and the reduction depended on the concentration of Thymol. Even at a low Thymol:PVB ratio of 0.2:1, the obtained antibacterial activity value against the Gram-positive S. aureus bacteria was 2.8, which indicated that this membrane had relevant antibacterial activity. By contrast, the antibacterial activity values of this membrane against the Gram-negative K. pneumoniae and E. coli bacteria were only 1.6 and 0.7 , respectively. According to the JIS L1902 description, the membrane thus had no relevant antibacterial activity. Therefore, the growth of inhibition was observed for Gram-positive bacteria even at a low concentration of Thymol as compared with the Gram-negative bacteria. This variation was also reported in previous research [34]. The Gram-negative bacteria were protected by cell-wall lipopolysaccharides and outer membrane proteins, which restrict the diffusion of hydrophobic compounds through the lipopolysaccharide layers. However, at a higher concentration of antimicrobial agents, the polysaccharide layer was destroyed by essential oils.

As illustrated in Figure 2d, the sample with ratio 0.6:1 had the highest activity, indicating that the bacterial counts of the three test bacteria after culture were all $<20$ colonyforming units (CFUs), meaning that all the bacteria died. Furthermore, when the Thymol:PVB ratio was increased to 0.8 and 1 , the antibacterial activity value did not change. Therefore, the Thymol:PVB ratio 0.6:1 (w:w) was the most suitable ratio for preparing the antibacterial nanofiber mask.

\subsubsection{Diameter of Nanofibrous Membrane for Thymol/PVB Blenders}

As shown in Figures 3 and 4, Thymol/PVB nanofiber membranes prepared with different proportions had an average fiber diameter between 500 and $700 \mathrm{~nm}$, which belonged to the broad range of nanofibers.

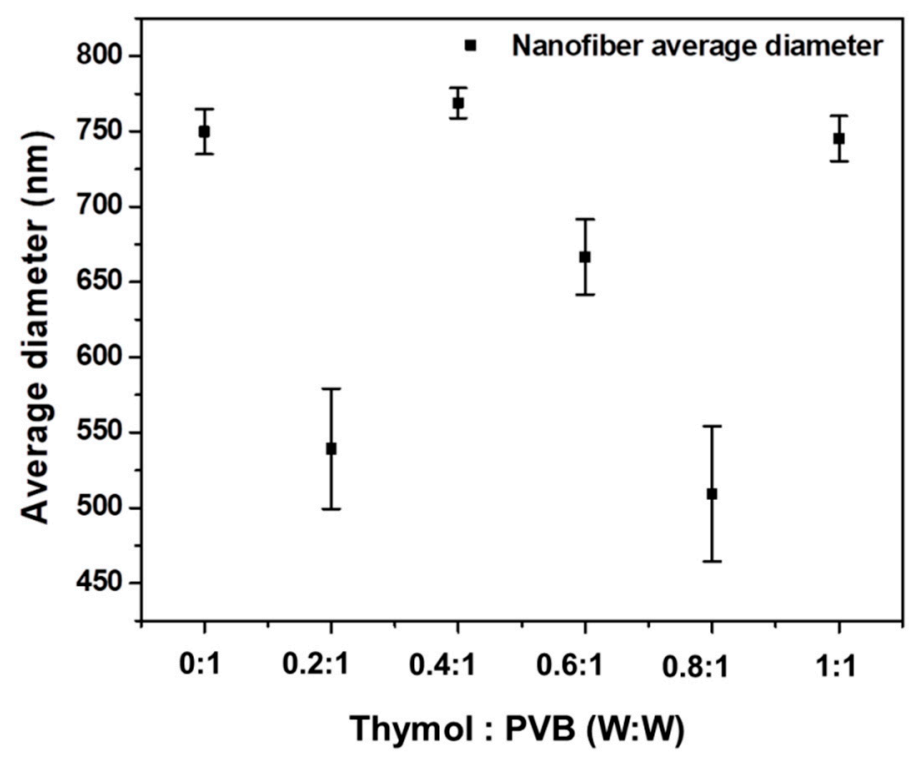

Figure 3. Diameter of nanofibrous membranes for Thymol/PVB blenders. 

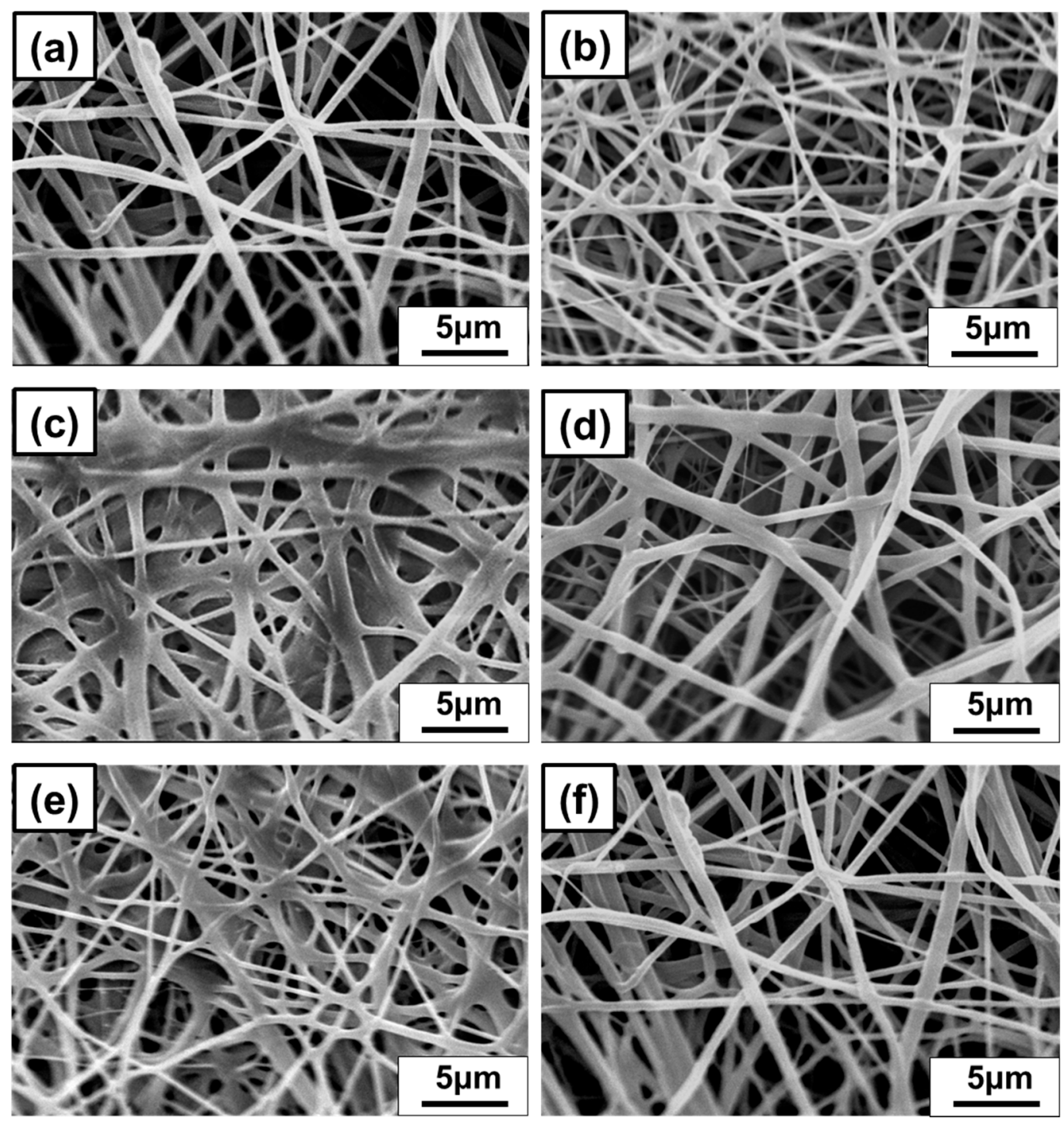

Figure 4. Nanofibrous membrane of Thymol/PVB blenders SEM pattern. (a) Thymol:PVB = 0:1, (b) Thymol:PVB = 0.2:1, (c) Thymol:PVB = 0.4:1, (d) Thymol:PVB = 0.6:1, (e) Thymol:PVB = 0.8:1, (f) Thymol:PVB = 1:1.

3.3. Analysis of the Protection Efficiency of Antibacterial Nanofiber Masks

3.3.1. Submicron Particulate Filtration Efficiency (PFE) and Pressure Difference of Air Exchange

The optimized ratio (0.6:1) Thymol/PVB antibacterial nanofiber masks were prepared using a vertical electrospinning device, and protection efficiency and pressure difference tests were conducted in accordance with the CNS 14,755 and CNS 14,777 standards. The electrospinning parameters employed are presented in Table S1, and the results are shown in Table 3. Groups C and D collected nanofiber webs at $25 \mathrm{kV}$ and $5 \mathrm{~mL} / \mathrm{h}$ for $45 \mathrm{~min}$, and although the collection distance was different for these groups, the PFE was $>80 \%$ for both. However, the pressure difference exceeded the $5 \mathrm{mmH}_{2} \mathrm{O} / \mathrm{cm}^{2}$ threshold specified by CNS 14,774 for surgical masks, indicating that the mask would cause breathing problems during wear. According to the parameter settings in Table S1, the influences of voltage and flow rate on the PFE, impedance, and pressure difference were explored. In Group $\mathrm{E}$, electrospinning was performed at the voltage of $15 \mathrm{kV}$ and flow rate of $2 \mathrm{~mL} / \mathrm{h}$. The test results revealed that the PFE was $82.7 \%$ and pressure difference was $4.5 \mathrm{mmH}_{2} \mathrm{O} / \mathrm{cm}^{2}$, which meets CNS 14,774 standard requirements for surgical masks. 
Table 3. Results of protection efficiency in different electrospinning parameters.

\begin{tabular}{|c|c|c|c|c|}
\hline \multirow{2}{*}{ Group } & \multirow{2}{*}{$\begin{array}{l}\text { Spinning Time } \\
\text { (min) }\end{array}$} & \multicolumn{2}{|c|}{ CNS 14755} & \multirow{2}{*}{$\begin{array}{c}\text { CNS } 14777 \\
\text { Pressure Difference } \\
\left(\mathrm{mmH}_{2} \mathrm{O} / \mathrm{cm}^{2}\right)\end{array}$} \\
\hline & & PFE (\%) & $\begin{array}{c}\text { Inspiratory Impedance } \\
\left(\mathrm{mmH}_{2} \mathrm{O}\right)\end{array}$ & \\
\hline $\mathrm{C}$ & 0 & $32.8 \pm 2.5$ & $3.9 \pm 0.3$ & $1.4 \pm 0.2$ \\
\hline $\mathrm{C}$ & 15 & $65.0 \pm 2.5$ & $9.1 \pm 0.9$ & $3.8 \pm 0.1$ \\
\hline $\mathrm{C}$ & 30 & $67.1 \pm 2.0$ & $11.4 \pm 0.6$ & $4.4 \pm 0.1$ \\
\hline $\mathrm{C}$ & 45 & $89.5 \pm 1.0$ & $38.7 \pm 0.8$ & $13.7 \pm 1.8$ \\
\hline $\mathrm{C}$ & 60 & $94.2 \pm 0.3$ & $54.2 \pm 8.6$ & $14.1 \pm 4.5$ \\
\hline $\mathrm{C}$ & 120 & $89.5 \pm 1.6$ & $42.7 \pm 4.9$ & $12.6 \pm 2.0$ \\
\hline $\mathrm{D}$ & 0 & $7.5 \pm 0.1$ & $1.8 \pm 0.1$ & $0.8 \pm 0.1$ \\
\hline $\mathrm{D}$ & 45 & $85.1 \pm 0.7$ & $29.9 \pm 0.4$ & $9.7 \pm 0.1$ \\
\hline $\mathrm{E}$ & 60 & $62.9 \pm 1.2$ & $7.3 \pm 0.2$ & $2.6 \pm 0.2$ \\
\hline $\mathrm{E}$ & 120 & $82.7 \pm 1.0$ & $12.3 \pm 0.4$ & $4.5 \pm 0.3$ \\
\hline
\end{tabular}

\subsubsection{The Fiber Diameter and PFE}

The fiber diameters were measured by SEM. Figure S2 and Table 4 exhibit that when the flow rate was reduced from $5 \mathrm{~mL} / \mathrm{h}$ to $2 \mathrm{~mL} / \mathrm{h}$, the average fiber diameter was reduced from $836 \pm 329 \mathrm{~nm}$ to $375 \pm 69 \mathrm{~nm}$. This result showed that as the flow rate decreased, the fiber diameter greatly decreased and became more uniform, and could effectively improve the impedance value and the high-pressure difference. For the nanofiber mask, the thinner and denser the fiber diameters are, the more PFE and pressure difference can meet the requirements of CNS 14,774 specifications for general medical masks [47].

Table 4. Comparison of fiber diameters in the middle layer of nanofiber masks.

\begin{tabular}{ccc}
\hline Group/Spinning Time & D/45 min & E/2 h \\
\hline Voltage & $25 \mathrm{kV}$ & $15 \mathrm{kV}$ \\
Flow rate & $5 \mathrm{~mL} / \mathrm{h}$ & $2 \mathrm{~mL} / \mathrm{h}$ \\
PFE $(\%)$ & 85.1 & 82.7 \\
Inspiratory impedance $\left(\mathrm{mmH}_{2} \mathrm{O}\right)$ & 29.9 & 12.3 \\
Pressure difference $\left(\mathrm{mmH}_{2} \mathrm{O} / \mathrm{cm}^{2}\right)$ & 9.7 & 4.5 \\
Average diameter $(\mathrm{nm})$ & 836 & 375 \\
Standard deviation & 329 & 69 \\
\hline
\end{tabular}

In the construction of general commercial masks, PP spun-bond is used as the outer and inner layers with a diameter of $20 \sim 30 \mu \mathrm{m}$. The middle layer is a melt-blown nonwoven fabric layer with 2-10 $\mu \mathrm{m}$ diameters. The fiber diameter of each nonwoven fabric was observed by SEM (Figure S2 and Table S7). However, most of the airborne viruses (Corona) spread through the aerosol are in nanometers [48-51]. The fiber diameter of the nanofiber prepared in this study was $375+69 \mathrm{~nm}$, and the filter efficiency was improved by reducing the fiber diameter. Hence, the antibacterial nanofibers are well replaceable for the nonwoven fabric layers.

\subsubsection{Spinning Parameters and PFE}

Although the electrospinning parameters of Group E can meet the specifications of CNS 14,774 mask, at $15 \mathrm{kV}$, the spinning solution was not able to form a stable tailor cone due to the droplets block in the needle nozzle. To overcome this, the applied voltage was increased to $18 \mathrm{kV}$ (Group F) and we found that the formation of beadles continuous nanofiber. The Group F parameters are given in Table S1 $(18 \mathrm{kV}$, distance $160 \mathrm{~mm}, 2 \mathrm{~mL} / \mathrm{h})$, under different spinning times. Correspondingly, the influence of PFE was further explained in Table S8, Figure 5, that as the spinning time increased, the accumulated nanofiber membranes increased. When the collection time reached $6 \mathrm{~h}$, the PFE increased from 38.6\% to $83.2 \%$, and the pressure difference was fixed at $4.7 \mathrm{mmH}_{2} \mathrm{O} / \mathrm{cm}^{2}$, which meets the requirements of CNS 14,774 [47]. 


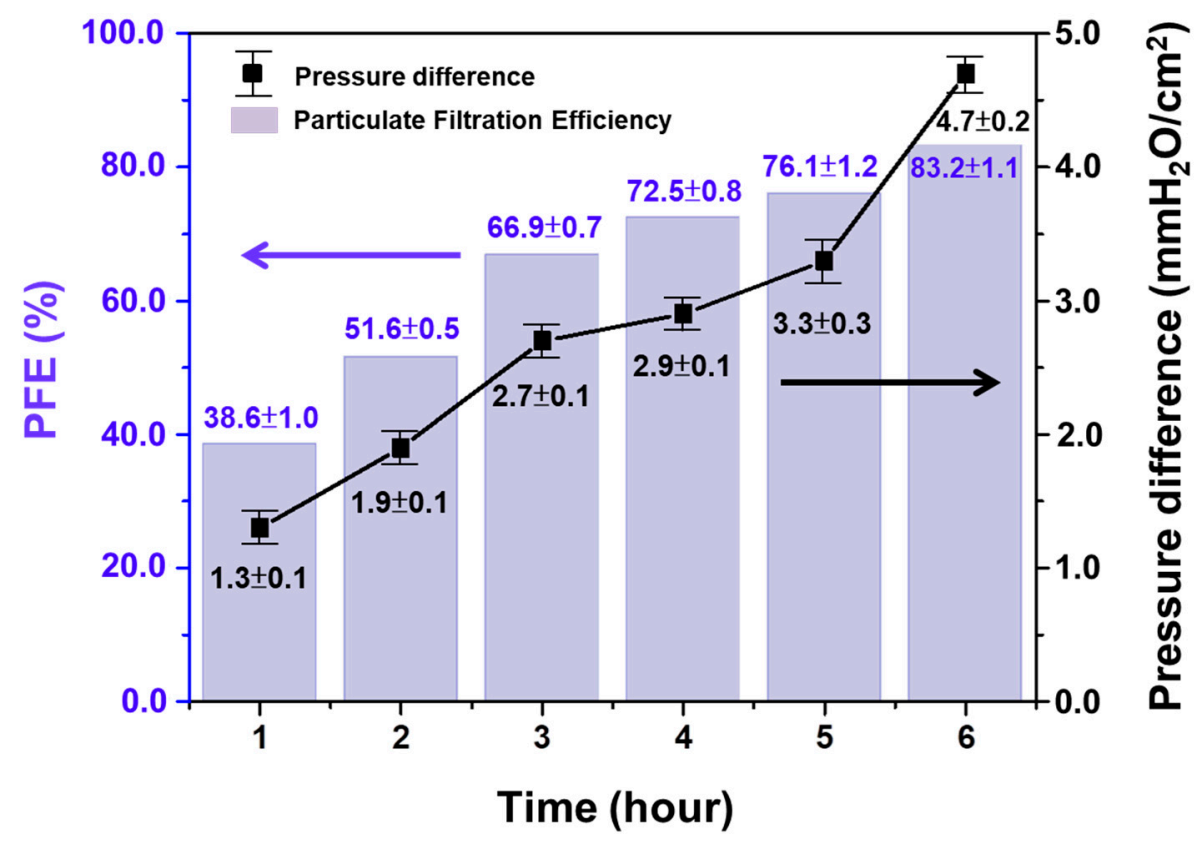

Figure 5. Testing results of particulate filtration efficiency (PFE) and pressure difference.

\subsubsection{Bacteria Filtration Efficiency (BFE)}

In Taiwan, general medical masks must meet the specifications of CNS 14774, which state that the BFE must be $>95 \%$. From the viewpoint of air permeation, the BFE and PFE of a filter material should be correlated. Therefore, in this study, 30 commercial masks were tested and analyzed to determine the correlation between their BFE and PFE. In addition, a Thymol/PVB nanofibrous membrane was prepared through electrospinning with the Group F parameters, with fiber collection lasting 1-6 h, and it was observed that increasing the nanofiber collecting time leads to the higher areal density nanofiber membrane, which helps to trap the bacteria aerosols. Furthermore, these BFE results were compared with the PFE data. As shown in Table S9, the correlation between BFE and PFE for the different masks were nonlinear, although when the PFE exceeded $73 \%$, the BFE reached its maximum. Therefore, in this study, we prepared the mask with the aim of achieving the PFE of $\geq 80 \%$ and then conducted the BFE test. In theory, if the BFE value exceeded $95 \%$, it could meet the CNS 14,774 specifications.

To demonstrate this, a BFE test was performed to the Group F nanofiber membrane by varying its electrospinning parameters. The results are shown in Figure 6 and Table S10. The PFE of the antibacterial nanofiber mask was $83.2 \%$, and its BFE was $99.4 \%$, which was consistent with the correlation in the data analysis, as shown in Figure 6h. Moreover, to support this, many other researchers also have investigated the filtration efficiency using the analytical methods on the porous fiber membranes [52,53]. 

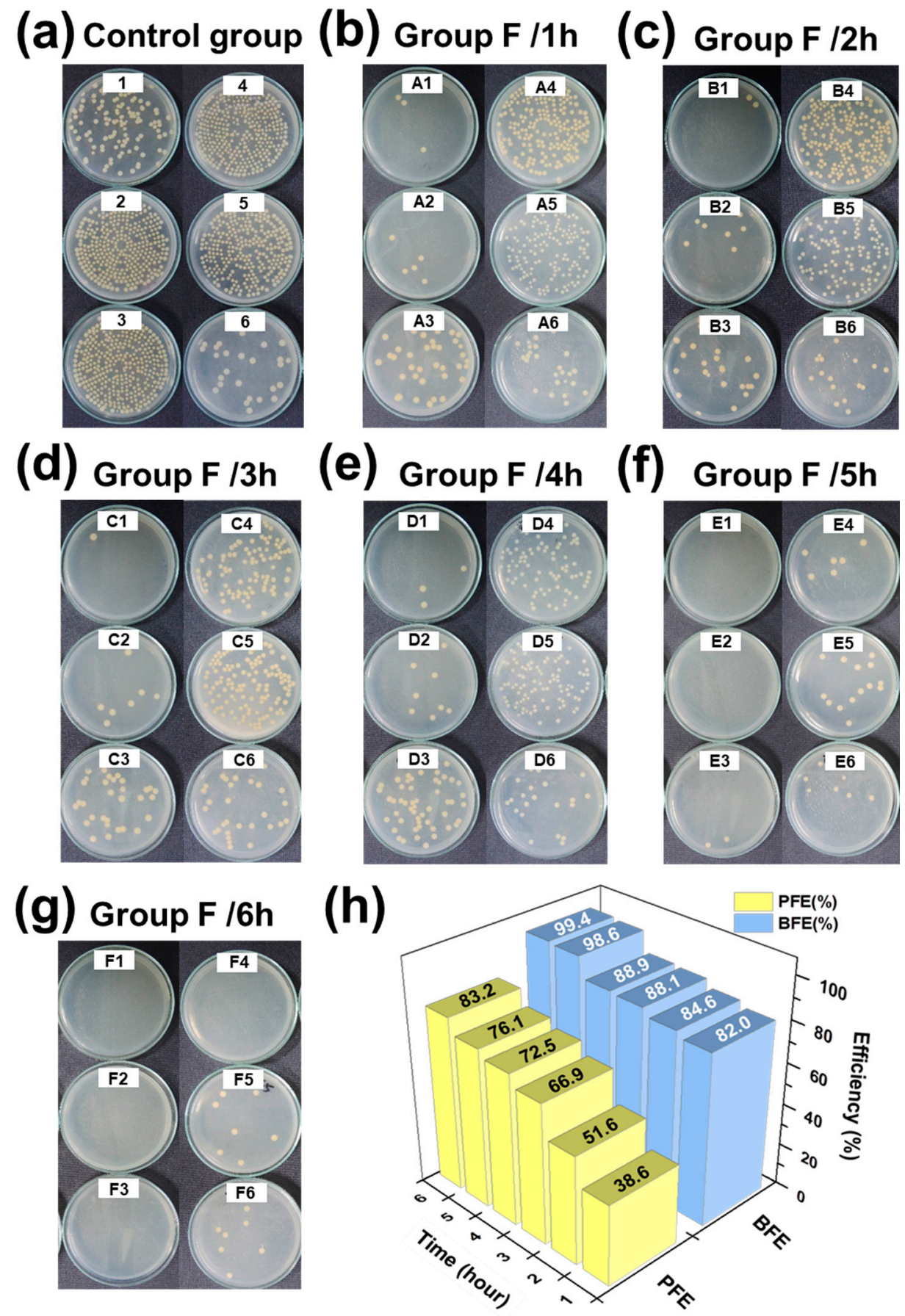

Figure 6. Bacterial filtration efficiency (BFE) test results of Group F spinning at different collection times. (a) Control group, (b) Group F/1h, (c) Group F/2h, (d) Group F/3h, (e) Group F/4h, (f) Group F/5h, (g) Group F/6h. (h) Correlation results of PFE and BFE tests in Group F.

\section{Conclusions}

An extension of industries may address their countries' growth, although it brings an inevitable side effect to their people. Especially, food and airborne diseases cause some serious issues. The face masks are an affordable and effective safety measure. Cost-effective bio-degradable eco-friendly masks are an inviting field of research due to increasing demands on healthcare and rising concerns of personal hygiene and safety. Through this research, we opened up a low-cost biodegradable face mask fabrication process, which can protect and sustain the human life. 
In this research, a Thymol/PVB composite nanofibrous membrane was produced with various optimization conditions for the antibacterial mask. As prepared, the Thymol: $\mathrm{PVB}=0.6: 1$ composite nanofibrous mask shows better performance, which meets the specifications of CNS 14774. Especially, bacterial filtration efficiency and pressure difference exhibit better performance than the commercial mask. Quantitative antibacterial activity test with JIS L1902 absorption method shows that as the content of Thymol increased, the antibacterial activity of Thymol/PVB nanofibrous membranes increased. The antibacterial activity values against Gram-positive bacteria of $S$. aureus and Gram-negative bacteria of K. pneumoniae and E. coli were 5.6 and 6.4, respectively. PFE values mainly depend on the electrospinning parameters. At $18 \mathrm{kV}, 2 \mathrm{~mL} / \mathrm{h}$, the PFE met $83.2 \%$, the inspiratory impedance was $10.8 \mathrm{mmH}_{2} \mathrm{O} / \mathrm{cm}^{2}$, and the pressure difference was $4.7 \mathrm{mmH}_{2} \mathrm{O} / \mathrm{cm}^{2}$, which fixes the respiration problem of the medical mask. BFE was $99.4 \%$, which also verified the correlation between $\mathrm{BFE}$ and PFE data analysis inferred in this study. That is, when PFE was $>73 \%$, BFE reached $\geq 99 \%$ or more. Based on the results, Thymol/PVB nanofibers can be an alternate membrane layer for this pandemic environment, which is expected to be used as a multifunctional antibacterial mask against bacteria and viruses.

Supplementary Materials: The following are available online at https:/ / www.mdpi.com/2073-436 0/13/7/1122/s1, Figure S1: Antibacterial qualitative results of Thymol/PVB nanofibrous membranes on Staphylococcus aureus, Figure S2: SEM image of the middle layer of the nanofibrous masks, Table S1: Parameters of the vertical electrospinning device, Table S2: Sample weight per unit area in various preparation methods, Table S3: Quantitative antibacterial properties of Thymol/PVB nanofibrous membrane against S. aureus, Table S4: Quantitative antibacterial activity of Thymol/PVB nanofibrous membrane against K. pneumonia, Table S5: Quantitative antibacterial activity of Thymol/PVB nanofibrous membrane against E. coli, Table S6: Comparison of antibacterial activity values of Thymol/PVB blenders against three bacteria strains, Table S7: Comparison of PP Spun-Bond and Melt-blown nonwoven fabrics, Table S8: Testing results of PFE and Pressure difference, Table S9: PFE and BFE test results of 30 commercial masks, Table S10: Protection efficiency of Thymol/PVB antibacterial nanofibrous masks.

Author Contributions: Conceptualization, C.-J.C., C.-C.K. and C.-H.L. are conceived and supervised the project. W.-C.L., C.-Y.C. and M.V. conceived designed the experiments. W.-C.L. and M.V. performed and analyzed the experiments. M.V. and C.-Y.C. assisted with sample preparation, analyzing the SEM morphology and the other measurement. W.-C.L. wrote the paper. W.-C.L., C.-C.K., C.-J.C., C.-H.L., S.-P.R., R.-H.L., W.-H.C. and Y.-Y.Y., discussed the results and revised or commented on the manuscript. All authors have read and agreed to the published version of the manuscript.

Funding: This research was funded by the Ministry of Science and Technology, Taiwan, (MOST 109-2622-E-027-004-CC3, MOST 109-2221-E-027-114 -MY3, and MOST 110-2222-E-027-001-MY2) and National Taipei University of Technology and Chang Gung Memorial Hospital Joint Research Program, (NTUT-CGMH-110-06) NTUT-CGMH Joint Research Program, for financial support.

Institutional Review Board Statement: Not applicable.

Informed Consent Statement: Not applicable.

Data Availability Statement: The data presented in this study are available on request from the corresponding author.

Conflicts of Interest: The authors declare no conflict of interest.

\section{References}

1. Wang, Q.; Bai, Y.; Xie, J.; Jiang, Q.; Qiu, Y. Synthesis and filtration properties of polyimide nanofiber membrane/carbon woven fabric sandwiched hot gas filters for removal of PM 2.5 particles. Powder Technol. 2016, 292, 54-63. [CrossRef]

2. Fikenzer, S.; Uhe, T.; Lavall, D.; Rudolph, U.; Falz, R.; Busse, M.; Hepp, P.; Laufs, U. Effects of surgical and FFP2/N95 face masks on cardiopulmonary exercise capacity. Clin. Res. Cardiol. 2020, 109, 1522-1530. [CrossRef]

3. Kim, M.C.; Bae, S.; Kim, J.Y.; Park, S.Y.; Lim, J.S.; Sung, M.; Kim, S.H. Effectiveness of surgical, KF94, and N95 respirator masks in blocking SARS-CoV-2: A controlled comparison in 7 patients. Infect. Dis. 2020, 52, 908-912. [CrossRef] [PubMed] 
4. Rengasamy, S.; Eimer, B.C.; Shaffer, R.E. Comparison of nanoparticle filtration performance of NIOSH-approved and CE-marked particulate filtering facepiece respirators. Ann. Occup. Hyg. 2009, 53, 117-128. [CrossRef] [PubMed]

5. Chalikonda, S.; Waltenbaugh, H.; Angelilli, S.; Dumont, T.; Kvasager, C.; Sauber, T.; Servello, N.; Singh, A.; Diaz-Garcia, R. Implementation of an Elastomeric Mask Program as a Strategy to Eliminate Disposable N95 Mask Use and Resterilization: Results from a Large Academic Medical Center. J. Am. Coll. Surg. 2020, 231, 333-338. [CrossRef]

6. Czubryt, M.P.; Stecy, T.; Popke, E.; Aitken, R.; Jabusch, K.; Pound, R.; Lawes, P.; Ramjiawan, B.; Pierce, G.N. N95 mask reuse in a major urban hospital: COVID-19 response process and procedure. J. Hosp. Infect. 2020, 106, 277-282. [CrossRef]

7. Bai, Y.; Han, C.B.; He, C.; Gu, G.Q.; Nie, J.H.; Shao, J.J.; Xiao, T.X.; Deng, C.R.; Wang, Z.L. Washable Multilayer Triboelectric Air Filter for Efficient Particulate Matter PM2.5Removal. Adv. Funct. Mater. 2018, 28, 1706680. [CrossRef]

8. Cho, C.-J.; Chen, S.-Y.; Kuo, C.-C.; Veeramuthu, L.; Au-Duong, A.-N.; Chiu, Y.-C.; Chang, S.-H. Morphology and optoelectronic characteristics of organic field-effect transistors based on blends of polylactic acid and poly(3-hexylthiophene). Polym. J. 2018, 50, 975-987. [CrossRef]

9. Jiang, D.H.; Chiu, P.C.; Cho, C.J.; Veeramuthu, L.; Tung, S.H.; Satoh, T.; Chiang, W.H.; Cai, X.; Kuo, C.C. Facile 3D Boron Nitride Integrated Electrospun Nanofibrous Membranes for Purging Organic Pollutants. Nanomaterials 2019, 9, 1383. [CrossRef]

10. Liang, F.-C.; Ku, H.-J.; Cho, C.-J.; Chen, W.-C.; Lee, W.-Y.; Chen, W.-C.; Rwei, S.-P.; Borsali, R.; Kuo, C.-C. An intrinsically stretchable and ultrasensitive nanofiber-based resistive pressure sensor for wearable electronics. J. Mater. Chem. C 2020, 8 , 5361-5369. [CrossRef]

11. Lu, W.C.; Chuang, F.S.; Venkatesan, M.; Cho, C.J.; Chen, P.Y.; Tzeng, Y.R.; Yu, Y.Y.; Rwei, S.P.; Kuo, C.C. Synthesis of Water Resistance and Moisture-Permeable Nanofiber Using Sodium Alginate-Functionalized Waterborne Polyurethane. Polymers 2020, 12, 2882. [CrossRef] [PubMed]

12. Veeramuthu, L.; Li, W.-L.; Liang, F.-C.; Cho, C.-J.; Kuo, C.-C.; Chen, W.-C.; Lin, J.-H.; Lee, W.-Y.; Wang, C.-T.; Lin, W.-Y.; et al. Smart garment energy generators fabricated using stretchable electrospun nanofibers. React. Funct. Polym. 2019, 142, 96-103. [CrossRef]

13. Veeramuthu, L.; Venkatesan, M.; Liang, F.C.; Benas, J.S.; Cho, C.J.; Chen, C.W.; Zhou, Y.; Lee, R.H.; Kuo, C.C. Conjugated Copolymers through Electrospinning Synthetic Strategies and Their Versatile Applications in Sensing Environmental Toxicants, $\mathrm{pH}$, Temperature, and Humidity. Polymers 2020, 12, 587. [CrossRef] [PubMed]

14. Chen, B.-Y.; Kuo, C.-C.; Cho, C.-J.; Liang, F.-C.; Jeng, R.-J. Novel fluorescent chemosensory filter membranes composed of electrospun nanofibers with ultra-selective and reversible $\mathrm{pH}$ and $\mathrm{Hg} 2+$ sensing characteristics. Dyes Pigment. 2017, 143, 129-142. [CrossRef]

15. Cho, C.-J.; Lu, S.-T.; Kuo, C.-C.; Liang, F.-C.; Chen, B.-Y.; Chu, C.-C. Pyrene or rhodamine derivative-modified surfaces of electrospun nanofibrous chemosensors for colorimetric and fluorescent determination of $\mathrm{Cu} 2+, \mathrm{Hg} 2+$, and $\mathrm{pH}$. React. Funct. Polym. 2016, 108, 137-147. [CrossRef]

16. Liang, F.C.; Kuo, C.C.; Chen, B.Y.; Cho, C.J.; Hung, C.C.; Chen, W.C.; Borsali, R. RGB-Switchable Porous Electrospun Nanofiber Chemoprobe-Filter Prepared from Multifunctional Copolymers for Versatile Sensing of $\mathrm{pH}$ and Heavy Metals. ACS Appl. Mater. Interfaces 2017, 9, 16381-16396. [CrossRef]

17. Liang, F.C.; Luo, Y.L.; Kuo, C.C.; Chen, B.Y.; Cho, C.J.; Lin, F.J.; Yu, Y.Y.; Borsali, R. Novel Magnet and Thermoresponsive Chemosensory Electrospinning Fluorescent Nanofibers and Their Sensing Capability for Metal Ions. Polymers 2017, 9, 136. [CrossRef]

18. Lin, C.C.; Jiang, D.H.; Kuo, C.C.; Cho, C.J.; Tsai, Y.H.; Satoh, T.; Su, C. Water-Resistant Efficient Stretchable Perovskite-Embedded Fiber Membranes for Light-Emitting Diodes. ACS Appl. Mater. Interfaces 2018, 10, 2210-2215. [CrossRef] [PubMed]

19. Chen, S.; Liu, G.-S.; He, H.-W.; Zhou, C.-F.; Yan, X.; Zhang, J.-C. Physical Structure Induced Hydrophobicity Analyzed from Electrospinning and Coating Polyvinyl Butyral Films. Adv. Condens. Matter Phys. 2019, 2019, 1-5. [CrossRef]

20. Peer, P.; Polaskova, M.; Musilova, L. Superhydrophobic poly(vinyl butyral) nanofibrous membrane containing various silica nanoparticles. J. Text. Inst. 2019, 110, 1508-1514. [CrossRef]

21. Fauzi, A.; Hapidin, D.A.; Munir, M.M.; Iskandar, F.; Khairurrijal, K. A superhydrophilic bilayer structure of a nylon 6 nanofiber/cellulose membrane and its characterization as potential water filtration media. RSC Adv. 2020, 10, 17205-17216. [CrossRef]

22. Keirouz, A.; Radacsi, N.; Ren, Q.; Dommann, A.; Beldi, G.; Maniura-Weber, K.; Rossi, R.M.; Fortunato, G. Nylon-6/chitosan core/shell antimicrobial nanofibers for the prevention of mesh-associated surgical site infection. J. Nanobiotechnol. 2020, 18, 51. [CrossRef] [PubMed]

23. Shi, L.; Zhuang, X.; Tao, X.; Cheng, B.; Kang, W. Solution blowing nylon 6 nanofiber mats for air filtration. Fibers Polym. 2013, 14, 1485-1490. [CrossRef]

24. Surgutskaia, N.S.; Martino, A.D.; Zednik, J.; Ozaltin, K.; Lovecká, L.; Bergerová, E.D.; Kimmer, D.; Svoboda, J.; Sedlarik, V. Efficient $\mathrm{Cu}^{2+}, \mathrm{Pb}^{2+}$ and $\mathrm{Ni}^{2+}$ ion removal from wastewater using electrospun DTPA-modified chitosan/polyethylene oxide nanofibers. Sep. Purif. Technol. 2020, 247, 116914. [CrossRef]

25. Song, X.; Song, Y.; Wang, J.; Liu, Q.; Duan, Z. Insights into the pore-forming effect of polyvinyl butyral (PVB) as the polymer template to synthesize mesoporous alumina nanofibers via electrospinning. Ceram. Int. 2020, 46, 9952-9956. [CrossRef] 
26. Cho, C.-J.; Chang, Y.-S.; Lin, Y.-Z.; Jiang, D.-H.; Chen, W.-H.; Lin, W.-Y.; Chen, C.-W.; Rwei, S.-P.; Kuo, C.-C. Green electrospun nanofiber membranes filter prepared from novel biomass thermoplastic copolyester: Morphologies and filtration properties. J. Taiwan Inst. Chem. Eng. 2020, 106, 206-214. [CrossRef]

27. Venkatesan, M.; Veeramuthu, L.; Liang, F.-C.; Chen, W.-C.; Cho, C.-J.; Chen, C.-W.; Chen, J.-Y.; Yan, Y.; Chang, S.-H.; Kuo, C.-C. Evolution of electrospun nanofibers fluorescent and colorimetric sensors for environmental toxicants, $\mathrm{pH}$, temperature, and cancer cells-A review with insights on applications. Chem. Eng. J. 2020, 397, 125431. [CrossRef]

28. Chan, H.W.; Cho, C.J.; Hsu, K.H.; He, C.L.; Kuo, C.C.; Chu, C.C.; Chen, Y.H.; Chen, C.W.; Rwei, S.P. Smart Wearable Textiles with Breathable Properties and Repeatable Shaping in In Vitro Orthopedic Support from a Novel Biomass Thermoplastic Copolyester. Macromol. Mater. Eng. 2019, 304, 1900103. [CrossRef]

29. Hsu, K.H.; Chen, C.W.; Wang, L.Y.; Chan, H.W.; He, C.L.; Cho, C.J.; Rwei, S.P.; Kuo, C.C. Bio-based thermoplastic poly(butylene succinate-co-propylene succinate) copolyesters: Effect of glycerol on thermal and mechanical properties. Soft Matter 2019, 15, 9710-9720. [CrossRef]

30. Marchese, A.; Orhan, I.E.; Daglia, M.; Barbieri, R.; Di Lorenzo, A.; Nabavi, S.F.; Gortzi, O.; Izadi, M.; Nabavi, S.M. Antibacterial and antifungal activities of thymol: A brief review of the literature. Food Chem. 2016, 210, 402-414. [CrossRef]

31. Michalska-Sionkowska, M.; Walczak, M.; Sionkowska, A. Antimicrobial activity of collagen material with thymol addition for potential application as wound dressing. Polym. Test. 2017, 63, 360-366. [CrossRef]

32. Marino, M.; Bersani, C.; Comi, G. Antimicrobial activity of the essential oils of Thymus vulgaris L. measured using a bioimpedometric method. J. Food Prot. 1999, 62, 1017-1023. [CrossRef] [PubMed]

33. Nostro, A.; Blanco, A.R.; Cannatelli, M.A.; Enea, V.; Flamini, G.; Morelli, I.; Sudano Roccaro, A.; Alonzo, V. Susceptibility of methicillin-resistant staphylococci to oregano essential oil, carvacrol and thymol. FEMS Microbiol. Lett. 2004, 230, 191-195. [CrossRef]

34. Kavoosi, G.; Dadfar, S.M.; Purfard, A.M. Mechanical, physical, antioxidant, and antimicrobial properties of gelatin films incorporated with thymol for potential use as nano wound dressing. J. Food Sci. 2013, 78, E244-E250. [CrossRef]

35. Karami, Z.; Rezaeian, I.; Zahedi, P.; Abdollahi, M. Preparation and performance evaluations of electrospun poly( $\varepsilon$-caprolactone), poly(lactic acid), and their hybrid (50/50) nanofibrous mats containing thymol as an herbal drug for effective wound healing. $J$. Appl. Polym. Sci. 2013, 129, 756-766. [CrossRef]

36. Koosehgol, S.; Ebrahimian-Hosseinabadi, M.; Alizadeh, M.; Zamanian, A. Preparation and characterization of in situ chitosan/polyethylene glycol fumarate/thymol hydrogel as an effective wound dressing. Mater. Sci. Eng. C Mater. Biol. Appl. 2017, 79, 66-75. [CrossRef]

37. Zhu, M.; Han, J.; Wang, F.; Shao, W.; Xiong, R.; Zhang, Q.; Pan, H.; Yang, Y.; Samal, S.K.; Zhang, F.; et al. Electrospun Nanofibers Membranes for Effective Air Filtration. Macromol. Mater. Eng. 2017, 302, 1600353. [CrossRef]

38. Kaźmierczak, D.; Guzińska, K.; Dymel, M. Antibacterial Activity of PLA Fibres Estimated by Quantitative Methods. Fibres Text. East. Eur. 2016, 24, 126-130. [CrossRef]

39. Pinho, E.; Magalhães, L.; Henriques, M.; Oliveira, R. Antimicrobial activity assessment of textiles: Standard methods comparison. Ann. Microbiol. 2010, 61, 493-498. [CrossRef]

40. Lee, S.-A.; Chen, Y.-L.; Hwang, D.-C.; Wu, C.-C.; Chen, J.-K. Performance Evaluation of Full Facepiece Respirators with Cartridges. Aerosol. Air Qual. Res. 2017, 17, 1316-1328. [CrossRef]

41. Bundjaja, V.; Santoso, S.P.; Angkawijaya, A.E.; Yuliana, M.; Soetaredjo, F.E.; Ismadji, S.; Ayucitra, A.; Gunarto, C.; Ju, Y.H.; Ho, M.H. Fabrication of cellulose carbamate hydrogel-dressing with rarasaponin surfactant for enhancing adsorption of silver nanoparticles and antibacterial activity. Mater. Sci. Eng. C Mater. Biol. Appl. 2021, 118, 111542. [CrossRef]

42. Deng, L.; Kang, X.; Liu, Y.; Feng, F.; Zhang, H. Effects of surfactants on the formation of gelatin nanofibres for controlled release of curcumin. Food Chem. 2017, 231, 70-77. [CrossRef]

43. Demirdogen, R.E.; Kilic, D.; Emen, F.M.; Aşkar, Ş.; Karaçolak, A.İ.; Yesilkaynak, T.; Ihsan, A. Novel antibacterial cellulose acetate fibers modified with 2-fluoropyridine complexes. J. Mol. Struct. 2020, 1204, 127537. [CrossRef]

44. Guzinska, K.; Kazmierczak, D.; Dymel, M.; Pabjanczyk-Wlazlo, E.; Bogun, M. Anti-bacterial materials based on hyaluronic acid: Selection of research methodology and analysis of their anti-bacterial properties. Mater. Sci. Eng. C Mater. Biol. Appl. 2018, 93, 800-808. [CrossRef] [PubMed]

45. NO, H.K.; Park, N.Y.; Lee, S.H.; Meyers, S.P. Antibacterial activity of chitosans and chitosan oligomers with different molecular weights. Int. J. Food Microbiol. 2002, 74, 65-72. [CrossRef]

46. Park, S.J.; Park, Y.M. Eco-dyeing and antimicrobial properties of chlorophyllin copper complex extracted from Sasa veitchii. Fibers Polym. 2010, 11, 357-362. [CrossRef]

47. Yim, W.; Cheng, D.; Patel, S.H.; Kou, R.; Meng, Y.S.; Jokerst, J.V. KN95 and N95 Respirators Retain Filtration Efficiency despite a Loss of Dipole Charge during Decontamination. ACS Appl. Mater. Interfaces 2020, 12, 54473-54480. [CrossRef] [PubMed]

48. Chowdhury, M.A.; Shuvho, M.B.A.; Shahid, M.A.; Haque, A.; Kashem, M.A.; Lam, S.S.; Ong, H.C.; Uddin, M.A.; Mofijur, M. Prospect of biobased antiviral face mask to limit the coronavirus outbreak. Environ. Res. 2021, 192, 110294. [CrossRef] [PubMed]

49. Das, O.; Neisiany, R.E.; Capezza, A.J.; Hedenqvist, M.S.; Forsth, M.; Xu, Q.; Jiang, L.; Ji, D.; Ramakrishna, S. The need for fully bio-based facemasks to counter coronavirus outbreaks: A perspective. Sci. Total Environ. 2020, 736, 139611. [CrossRef] [PubMed]

50. El-Atab, N.; Qaiser, N.; Badghaish, H.; Shaikh, S.F.; Hussain, M.M. Flexible Nanoporous Template for the Design and Development of Reusable Anti-COVID-19 Hydrophobic Face Masks. ACS Nano 2020, 14, 7659-7665. [CrossRef] 
51. Fadare, O.O.; Okoffo, E.D. Covid-19 face masks: A potential source of microplastic fibers in the environment. Sci. Total Environ. 2020, 737, 140279. [CrossRef]

52. Xiao, B.; Huang, Q.; Chen, H.; Chen, X.; Long, G. A Fractal Model for Capillary Flow through a Single Tortuous Capillary with Roughened Surfaces in Fibrous Porous Media. Fractals 2021, 29, 2150017. [CrossRef]

53. Xiao, B.; Wang, W.; Zhang, X.; Long, G.; Fan, J.; Chen, H.; Deng, L. A novel fractal solution for permeability and Kozeny-Carman constant of fibrous porous media made up of solid particles and porous fibers. Powder Technol. 2019, 349, 92-98. [CrossRef] 